\title{
A GESTÃO DA INFORMAÇÃO EM EQUIPES VIRTUAIS NO PODER JUDICIÁRIO: desafios para uma comunicação eficiente e segura.
}

\section{Rafael Lima da Costa ${ }^{1}$}

\section{RESUMO}

A virtualização do Poder Judiciário impõe uma mudança cultural que impacte no planejamento estratégico dos processos internos de tratamento e compartilhamento de informações entre os membros das equipes virtuais. Este estudo busca verificar a existência de riscos oriundos dessa virtualização e se há a possibilidade de implantação de métodos e instrumentos para uma comunicação eficiente e segura. Foram realizadas revisão teórica e pesquisa quantitativa e qualitativa para abordagem multidisciplinar. Conclui-se que existem riscos decorrentes da falta de protocolos para o compartilhamento de informações, com a apresentação de proposições para minimizá-los.

Palavras-Chave: Comunicação; Equipes Virtuais; Gestão; Judiciário.

\section{INFORMATION MANAGEMENT IN VIRTUAL TEAMS IN THE JUDICIARY: challenges for an efficient and safe communication.}

The virtualization of the Judiciary imposes a cultural change that impacts on the strategic planning of internal processes of treatment and sharing of information among the members of the virtual teams. This study seeks to verify the existence of risks arising from this virtualization and whether there is the possibility of implementing methods and instruments for efficient and safe communication. Theoretical review and quantitative and qualitative research were carried out for a multidisciplinary approach. It is concluded that there are risks arising from the lack of protocols for the sharing of information, with the presentation of propositions to minimize them.

\section{INTRODUÇÃO}

Um dos desafios para a gestão das denominadas equipes virtuais é o relacionado à comunicação entre os membros dessas equipes. Quando se atua no âmbito virtual, aumenta-se a dificuldade na troca de informações, principalmente em razão da ampliação da utilização de sistemas de informática para esse fim.

O objetivo do presente artigo é analisar a problemática da comunicação entre os membros das equipes que estão atuando de maneira remota no Poder Judiciário. Busca-se responder os seguintes questionamentos: A virtualização do Poder Judiciário aumenta os riscos para as atividades desenvolvidas? Como estruturar as atividades judiciais para

\footnotetext{
${ }^{1}$ Aluno do Programa de Mestrado Profissional em Direito e Poder Judiciário da Escola Nacional de Formação e Aperfeiçoamento de Magistrados, Especialista em Direito Processual Civil, Especialista em Direito Administrativo, Juiz Federal do Tribunal Regional Federal da $1^{a}$ Região.
} 
incrementar a eficiência e segurança do serviço público frente à nova realidade decorrente de sua virtualização?

O desenvolvimento do estudo é feito utilizando como métodos de pesquisa a revisão bibliográfica sobre a gestão estratégica de equipes virtuais e emprego de pesquisa quantitativa e qualitativa sobre os instrumentos e métodos de gestão que estão sendo utilizados para a comunicação entre os membros dessas equipes.

A hipótese defendida neste artigo é a de que a comunicação deve ser clara o suficiente para evitar dúvidas em relação aos comandos instituídos, bem como deve ser realizada com lastro em protocolos formalmente estabelecidos, por meio de instrumentos seguros, institucionalmente aceitos, para evitar não conformidades e vazamentos que possam colocar em risco a credibilidade da organização ou mesmo a efetividade do processo judicial.

\section{REVISÃO CONCEITUAL E TEÓRICA}

\subsection{O elemento humano na gestão estratégica para o aprimoramento da governança no Poder Judiciário}

A busca pela melhoria da eficiência nos serviços públicos prestados à população já ensejou reformas profundas na Administração Pública brasileira desde a década de 90. Em relação ao Poder Judiciário não foi diferente, com a ampla reforma realizada por meio da Emenda à Constituição $n^{\circ} 45$ de 2004. Em seu aspecto mais impactante, houve a criação do Conselho Nacional de Justiça, que passou a realizar o controle administrativo, e a traçar a missão e objetivos institucionais do Judiciário.

Além da reestruturação das instituições nacionais e do processo de desestatização de atividades classificadas como não essenciais, o reposicionamento do papel dos agentes públicos apresenta-se como elemento essencial ao desenvolvimento da Administração Pública. A reorganização dos servidores é, inclusive, um dos principais elementos da mencionada proposta de reforma administrativa.

Para Bresser-Pereira (2008), a eficiência do serviço público não depende apenas de ser realizado de forma profissional, mas também de os servidores públicos posicionados em alto escalão, ou seja, aqueles que detêm o poder para conduzir as políticas públicas, terem maior autonomia e serem responsáveis por seus atos decisórios. O referido autor denomina de 
"modelo estrutural de gerência pública" o que tem por foco mudanças na gestão de pessoas, além de uma administração por objetivos e reforma estrutural da organização do Estado.

$\mathrm{O}$ aspecto relevante desse modelo e que interessa ao presente estudo é a distinção realizada entre os serviços que integram o núcleo estratégico do Estado e aqueles que podem ser delegados a agências ou mesmo terceirizados para a iniciativa privada.

Não obstante o reconhecimento da necessidade de que o Poder Judiciário se adapte aos novos anseios sociais, moldando sua estrutura às alterações da sociedade em que está inserido, ainda não se logrou delinear modelo que afaste a atividade jurisdicional do núcleo estratégico do Estado, por ser considerada uma atividade essencial e que deve ser prestada por ele. Isso inviabiliza sua delegação integral a terceiros, notadamente do setor privado. Não impede, contudo, a sua modernização.

Com a reforma do Poder Judiciário e a criação do Conselho Nacional de Justiça, adotou-se formalmente um modelo gerencialista. Fernandes, Gengemi, F. Sauerbronn e J. Sauerbronn (2015) expõem que para esse fim houve a implantação de ferramenta oriunda da iniciativa privada denominada Balanced Scorecard (BSC), com ajustamentos necessários em razão de peculiaridades da atividade judicial. A eficiência e efetividade da atividade judicial são o foco desse modelo adotado no judiciário. Foram delineadas as dimensões do BSC em recursos, processos internos e sociedade.

Dentre as atividades do Conselho Nacional de Justiça, Chaer, Azevedo e Bonifácio (2009) citam o desafio da criação de um sistema integrado de gestão, o qual foi abordado no Encontro Nacional do Judiciário, que ocorreu em agosto de 2008, em Brasília. Apontam, ainda, a realização de encontros regionais posteriores, que tiveram por objetivo conhecer as boas práticas e realidades locais, como forma de viabilizar um amplo diagnóstico do judiciário.

Como consequência dessas reuniões, passou-se a analisar a gestão de recursos financeiros, humanos e de tecnologia da informação, bem como os níveis de qualificação dos profissionais da Justiça. Além disso, foram avaliados o grau de otimização dos processos fundamentais de trabalho e o desenvolvimento e execução da gestão com planejamento. $\mathrm{O}$ estímulo à comunicação e troca de experiências entre os Tribunais também foram desideratos dos aludidos encontros.

Importante destacar que um dos pilares para a melhoria da gestão foi a valorização e qualificação dos recursos humanos, com foco na gestão por competências. Assim, a 
articulação de objetivos estratégicos, com a fixação de metas e elaboração de projetos alterou de forma substancial a maneira como magistrados, servidores e demais colaboradores passaram a atuar e ser cobrados pela cúpula dos órgãos judiciais. O alinhamento de todos à estratégia da organização é um dos desafios do gestor público que está submetido a essa perspectiva gerencialista.

Reconheceu-se, portanto, que a estrutura do judiciário e a sua gestão podem receber a mesma influência que recebeu o setor privado nas últimas décadas, na busca da melhoria da governança. Governança diz respeito à gestão de organizações, com o delineamento de estruturas que permitam que elas sejam administradas, como bem define Hughes (2010).

Akutsu e Aquino (2012) defendem que a governança pode ser transposta das organizações privadas para a gestão pública, pois está relacionada ao sistema de controle das organizações. Um dos elementos que os referidos autores fazem referência na definição de governança é o reconhecimento de que, além da dinâmica do processo e regras do jogo, ela também trata dos fatores que organizam a interação entre os atores.

No âmbito interno, em razão do preponderante caráter intelectual das atividades desenvolvidas pelo Poder Judiciário, o elemento humano tem sua essencialidade evidenciada e necessita ser considerado no processo produtivo.

Motta (2010) identifica, porém, importante problema na inter-relação entre os magistrados e os agentes públicos do setor administrativo do Poder Judiciário que pode prejudicar a adoção de formas mais participativas e eficazes de gestão. Essa dificuldade seria decorrente do alto grau de autonomia que tanto os magistrados quanto os referidos agentes públicos teriam em sua atuação individual, o que criaria uma separação bem definida entre as atividades desenvolvidas pelo setor técnico do Judiciário e a área administrativa.

Esse delineamento da função judicante como algo realizado de forma isolada pelo magistrado, que necessita analisar de maneira individualizada as demandas da sociedade que são postas à sua apreciação por meio dos processos judiciais é um fator limitante para a sistematização de métodos mais ágeis de solução de litígios e da própria gestão judicial.

Mesmo dentro das equipes do setor técnico do Poder Judiciário, que costumam ser compostas por profissionais com excelente qualificação, há uma divisão rigorosa entre as atribuições, o que acarreta na concentração de praticamente a totalidade dos atos decisórios em um de seus integrantes, que é o magistrado. 
Se o plano normativo estabeleceu a necessidade de se seguir esse modelo, o crescimento exponencial do número de demandas que são distribuídas diariamente no Poder Judiciário impõe a sistematização de meios para que haja um aumento da produtividade. Essa melhoria da quantidade e qualidade dos atos jurisdicionais proferidos depende, então, da organização do quadro de servidores que auxiliam o magistrado, seja na prática de atividades administrativas que possibilitam a tramitação mais célere dos processos até o seu julgamento ou mesmo na atuação mais próxima da atividade-fim, no assessoramente direto do magistrado.

O trabalho artesanalmente realizado deve ceder espaço, portanto, ao trabalho em equipe, que necessita de colaboração, interação e comunicação. Para Chiavenato (2015) esses fatores favorecem a obtenção de resultados positivos.

Como bem apontam Hoegl e Gemuenden (2001) a comunicação é um dos elementos básicos para a qualidade do trabalho em equipe. A qualidade dessa comunicação é medida de acordo com a frequência, formalidade e abertura no seu compartilhamento. A frequência diz respeito ao tempo em que os membros da equipe passam comunicando-se entre si. Já a formalidade está relacionada à necessidade ou não de adoção de planejamento para sua realização, como agendamento ou marcação de reuniões. A abertura é a capacidade de a equipe trocar informações sem que elementos importantes sejam omitidos, para que haja transparência e confiança entre todos.

Em equipes bem estruturadas a comunicação é realizada de forma direta, aberta, com a retirada de intermediários que podem prejudicar a transmissão e assimilação da informação, sem que isso signifique em uma desorganização das atividades. Isso também aproxima o gestor de todos os membros da equipe, com valorização do elemento humano.

\subsection{Desafios decorrentes da virtualização do Poder Judiciário}

O Brasil vive desde o ano de 2014 crise econômica sem precedentes. O Produto interno bruto brasileiro recuou 5,9\% até 2020 (IBGE, 2021), impactando diretamente nos serviços públicos prestados, o que inclui os do Poder Judiciário. A Emenda Constitucional no 95 instituiu novo regime fiscal em nosso país, com limitação do crescimento das despesas públicas durante 20 anos. Essa crise foi agravada pela pandemia de Sars-Cov-2 ou COVID-19 que nos assola desde o primeiro semestre de 2020. 
A modernização do Poder Judiciário é um elemento essencial para a própria continuidade das suas atividades, uma vez que se por um lado a Emenda Constitucional $\mathrm{n}^{\circ} 95$ impõe a limitação de despesas públicas, por outro o número de novas demandas cresce. De acordo com o Relatório Justiça em Números do Conselho Nacional de Justiça (2021) houve um acréscimo no acervo do Poder Judiciário de 6,8\% de novos casos se comparado ao ano anterior. Assim, ao fim de 2019 existiam 77,1 milhões de processos pendentes de alguma solução definitiva.

Apesar de a consolidação de ferramentas tecnológicas, como o processo judicial eletrônico - PJE, auxiliar no enfrentamento da crise econômica e orçamentária, isso não é suficiente. Ainda de acordo com o Relatório Justiça em Números, o Poder Judiciário alcançou a cifra de $\mathrm{R} \$ 100,2$ bilhões em gastos no ano de 2019. Desse montante, 90,2\% representam gastos com pessoal.

Deve ser reconhecido que há dificuldade de redução das despesas com pessoal, seja pela previsão do art. 37, XV, da Constituição Federal, que garante a irredutibilidade de vencimentos, seja pela necessidade de manutenção de um quadro técnico extremamente qualificado em razão da própria natureza das atividades desenvolvidas. Ainda que a inteligência artificial esteja sendo desenvolvida para tentar contribuir com a eficiência da atividade judicante, ela ainda se apresenta de forma incipiente, fazendo com que o elemento humano ainda seja primordial para o ato de julgar.

Em sendo assim, a utilização da tecnologia na organização judiciária foi uma das formas encontradas para tentar modernizar o Poder Judiciário. Seguindo a tendência que já se verifica em diversas organizações, principalmente da iniciativa privada, a digitalização dos processos e ampliação do processo judicial eletrônico também representaram uma maneira de reduzir custos que estavam atrelados à tramitação física e guarda do acervo, além da estrutura para acomodação de pessoal (PARDINI et al., 2013).

Desse modo, diversas atividades foram eliminadas, espaços físicos foram reestruturados, com a consequente diminuição de despesas, sem perda de eficiência. As circunstâncias obrigaram a se fazer mais com menos recursos, com o afastamento da crença limitante de que a única forma de melhorar o serviço prestado pelo Poder Judiciário é com a sua ampliação estrutural (HADDAD E PEDROSA, 2017).

A virtualização do acervo processual implica em diversas questões que deverão impor mudança na cultura organizacional do Poder Judiciário. Uma delas é a não transferência para 
o ambiente virtual das mesmas características de gestão dos processos físicos, o que inclui a forma de liderança do juiz sobre os colaboradores e a forma de controle das informações que tramitam internamente entre as equipes de servidores e juízes.

\subsubsection{Equipes virtuais e o Poder Judiciário}

Albuquerque (2020) expõe que as equipes podem ser vistas como sistemas relacionais, uma vez que seus membros interconectam-se por meio de tarefas integradas a um ou vários processos, sempre em busca de um objetivo conhecido e comum.

Por sua vez, equipes virtuais são na definição de Townsend, DeMarie e Hendrickson (1998) o grupo de pessoas disperso organizacional e territorialmente que se mantém conectado por meio da utilização de uma combinação de tecnologias de informação e telecomunicação para que possa desempenhar determinada tarefa.

Essas equipes virtuais que tiveram sua relevância percebida em razão do processo de globalização da economia e do desenvolvimento das tecnologias da informação, notadamente a internet, são geridas por líderes digitais, como aponta Albuquerque (2020). São denominados de líderes digitais, uma vez que a relação com a equipe deve ser feita pelo meio digital, como forma de possibilitar a extração do seu máximo desempenho.

Sobre as equipes virtuais, Townsend, DeMarie e Hendrickson (1998) acrescenta que a mudança do modelo de atuação presencial decorre, além da mencionada globalização, de alguns outros fatores específicos como o aumento da prevalência de estruturas organizacionais planas ou horizontais, a mudança na expectativa de participação dos trabalhadores nas organizações e continuidade da alteração de atividades de produção para um ambiente de trabalho intelectual.

É certo que o ambiente virtual permite a desterritorialização seja de uma pessoa, de um ato, de uma informação ou mesmo de uma coletividade. Há, assim, uma separação do espaço geográfico e da própria temporalidade ordinariamente medida (LÉVY, 2011). Entretanto, essa virtualização não impossibilita e até mesmo exige a manutenção de uma referência institucional e temporal, o que vai lhe conferir concretude e controle, ainda que possa não ser necessária qualquer reunião física entre seus membros.

Quando não é organizado de forma a levar em consideração cada integrante da equipe que irá atuar nesse ambiente virtual, pode acarretar em desestruturação do grupo, sensação de 
não pertencimento e a própria desumanização da atividade. Alterações que atinjam um dos membros da equipe podem acarretar em prejuízo ao conjunto. Nessa visão de equipe como sistema relacional, o seu líder possui o papel de reconhecer que ela possui uma identidade própria, com os valores que foram sendo introduzidos e que se consolidam com o tempo (ALBUQUERQUE, 2020).

Desse modo, o ambiente computacional digital concretiza o virtual. Isso permite a reorganização do tempo para a prática de atividades, que antes estavam limitadas ao tradicional expediente de trabalho.

O Poder Judiciário pode se beneficiar dessa evolução tecnológica e da forma como as pessoas se relacionam com o ambiente de trabalho. Para isso, porém, não basta implantar um modelo de administração gerencial focado no alcance de metas (tutela jurisdicional célere) e na satisfação do jurisdicionado, sem que o gestor acompanhe a evolução de cada membro da equipe, para que possa auxiliá-lo na superação de eventuais dificuldades (SILVA, 2020).

Uma das vantagens do trabalho em ambiente virtual é a satisfação que costuma ser causada no trabalhador em razão da flexibilidade de horários e ausência de deslocamento até o local de trabalho possibilitando transpor questões de tempo e de possíveis transtornos relativos à mobilidade urbana, o que favorece o desenvolvimento de atividades pessoais, como o contato com a família (TREMBLAY, 2002). Isso pode não trazer o incremento de eficiência esperado quando não há um direcionamento claro das atividades que devem ser realizadas, bem como a manutenção da sinergia com o restante do grupo, o que é papel do líder da equipe garantir. No âmbito do Poder Judiciário, a gestão de equipes, sejam presenciais ou virtuais apresenta-se ainda mais desafiadora, em razão da sua tradição organizacional hierarquizada.

Costuma-se aferir a eficiência de um magistrado pela produtividade no desenvolvimento da sua atividade-fim, que consiste na prolação de despachos, decisões e sentenças/acórdãos e, para tanto, o próprio Conselho Nacional de Justiça estabelece metas a serem atingidas. Assim, muitos juízes concentram seus esforços na atividade-fim, delegando a gestão da unidade judiciária para os servidores, sem participar efetivamente da elaboração e implantação de medidas para a concretização, no âmbito local, do planejamento estratégico nacional elaborado pelo CNJ e pelos Tribunais aos quais estão vinculados.

Ocorre que o magistrado também possui o relevante papel de gestor de uma unidade judiciária e dos membros que integram a equipe de trabalho. É essencial, pois, que participe 
da elaboração de rotinas, fluxos de atividade e controle de cada etapa da tramitação processual de maneira desburocratizada e eficiente, bem como realize efetivamente a gestão de pessoas. Para atingir esse objetivo, deve utilizar as ferramentas tecnológicas adequadas para a nova realidade enfrentada pelo Poder Judiciário e contar com o auxílio de servidores capacitados e motivados.

\section{A COMUNICAÇÃO ENTRE OS MEMBROS DAS EQUIPES VIRTUAIS NO PODER JUDICIÁRIO}

Com a pandemia da COVID-19, o processo de virtualização do Poder Judiciário foi acelerado. No âmbito do Tribunal Regional Federal da $1^{\text {a }}$ Região, foram adotadas medidas temporárias de prevenção e redução dos riscos de disseminação e contágio da COVID-19 por meio da Resolução PRESI 9553729 e por resoluções subsequentes.

Desse modo, todo o planejamento para a transferência do acervo físico de processos para o ambiente virtual necessitou ser refeito, antecipando a digitalização dos processos e os canais de atendimento remoto, uma vez que o manuseio de autos físicos e acesso de servidores às unidades judiciárias ficaram prejudicados em razão da imposição de medidas de restrições sanitárias.

A implantação do teletrabalho, das audiências virtuais, a permissão para a realização de teleperícia, atendimento de advogados e partes por meio de videoconferência, foram fatores que contribuíram para o aumento do número de atos judiciais praticados. Essas ferramentas digitais demonstraram a tentativa de o Judiciário respeitar o jurisdicionado, garantindo a resolução de litígios, sem violar as regras sanitárias estabelecidas (FARIAS, 2020).

Com essa virtualização compulsória pela situação de calamidade pública oriunda da pandemia, praticamente a totalidade da comunicação entre os membros do Poder Judiciário e os servidores passou a ser realizada por meio de sistemas de informática e telemática.

O problema é relevante, pois se dentro do processo judicial eletrônico existem mecanismos para controle do acesso aos dados ali inseridos, antes da introdução de tais informações no ambiente digital do PJE o controle e gestão é determinado por cada unidade judiciária. 
No Tribunal Regional Federal da $1^{\text {a }}$ Região tentou-se sistematizar os trabalhos realizados pelas equipes de servidores de cada unidade judiciária no âmbito virtual, por meio da Circular COGER - 10105456. Por se tratar de recomendação, não foram criados, porém, meios de controle efetivo das informações partilhadas pelo meio digital entre os servidores e os juízes.

É comum a troca de informações entre membros da equipe antes de o ato ser inserido no processo judicial eletrônico. Em uma relação interpessoal desenvolvida em qualquer organização existem a comunicação informal e a formal. No âmbito presencial, muitas vezes essas formas de comunicação praticamente se fundem. Por sua vez, quando essa comunicação é realizada entre membros de equipes virtuais o uso do intermediário eletrônico exige um cuidado especial.

Pelos motivos expostos, analisar se esses dados estão sendo organizados e manuseados de forma segura, para evitar vazamentos, é um dos objetivos do presente estudo, ante o risco à efetividade da atividade jurisdicional e por ser imperioso o respeito à privacidade, notadamente em razão da repercussão que uma vida conectada em rede de computadores pode gerar (MAGRANI, 2019).

\subsection{Metodologia da pesquisa}

Esta pesquisa foi estruturada em 3 etapas. A primeira delas consistiu em revisão teórica sobre governança pública, gestão no Poder Judiciário e equipes virtuais. Em um segundo momento, para tentar identificar um padrão de atuação dos magistrados na gestão da comunicação das equipes virtuais, este autor realizou pesquisa quantitativa e qualitativa, por meio de questionário apresentado no âmbito eletrônico e compartilhado com magistrados e magistradas federais, entre 08 e 12 de julho de 2021. Trata-se de uma pesquisa preliminar sobre o tema e buscou-se alcançar juízes e juízas federais de todos os Tribunais Regionais Federais para identificar eventuais diferenças nos métodos adotados entre eles.

O questionário foi composto por 10 perguntas objetivas que abordavam aspectos relacionados à gestão da informação e comunicação no período de plantão extraordinário decorrente da pandemia da Covid-19, com ênfase nos métodos e instrumentos utilizados pelos magistrados para o contato com os membros das equipes que foram colocadas em trabalho virtual.

Foi respondido por 29 juízes e juízas federais, na sua maioria integrantes do Tribunal Regional Federal da $1^{\mathrm{a}}$ Região (dois juízes do Tribunal Regional Federal da $5^{\mathrm{a}}$ Região e 01 do 
Tribunal Regional Federal da $2^{a}$ Região). Não houve respostas por juízes ou juízas federais da $3^{\mathrm{a}}$ e $4^{\mathrm{a}}$ regiões.

Os participantes são lotados em localidades diversas, distribuídas pelas seções judiciárias da Bahia (02), Mato Grosso (01), Maranhão (12), Pará (4), Rondônia (01), Distrito Federal (01), Goiás (01), Minas Gerais (02), Amazonas (02), Ceará (01), Pernambuco (01) e Espírito Santo (01). A limitação da pesquisa a juízes e juízas federais justifica-se pela maior facilidade do contato do pesquisador, o que permitirá aprofundamento futuro do seu objeto.

A terceira etapa consistiu na análise dos dados obtidos. Dos magistrados que responderam a pesquisa, 6 (21\%) asseveraram que durante o plantão extraordinário decorrente da pandemia da COVID-19 não foram organizados em suas unidades judiciárias protocolos específicos para a troca de informações relacionadas a processos judiciais entre os membros da equipe que atuam de forma virtual.

Por sua vez, 12 (41\%) afirmaram não ter conhecimento de qualquer regulamentação ou mesmo recomendação do Tribunal acerca dos instrumentos tecnológicos para comunicação entre membros da equipe virtual.

Constatou-se que $21 \%$ dos participantes não adotaram qualquer protocolo diferenciado para troca de informações entre os membros das equipes de trabalho, não obstante todos os servidores estejam atuando de forma remota, pois há proibição de comparecimento presencial às sedes do Poder Judiciário, como medida preventiva de contaminação e contágio da Covid19.

Por outro viés, deve-se considerar que a não adoção de protocolos específicos para a troca de informações nesse período pode ser atribuído ao próprio desconhecimento das ferramentas tecnológicas disponibilizadas pelo Tribunal ou a melhor forma de sua utilização. Apenas 5\% dos juízes que afirmaram conhecer a existência de regulamentação ou recomendação do Tribunal acerca de instrumentos tecnológicos para comunicação entre membros de equipes virtuais responderam não ter adotado protocolos específicos para a troca de informações.

Dos pesquisados, 59\% (17) responderam que utilizam de forma preponderante o aplicativo de troca de mensagens do Microsoft Teams como instrumento tecnológico para a comunicação com a equipe que atua de forma remota e $41 \%$ (12) utilizam o aplicativo de mensagens Whatsapp. Não houve qualquer referência ao e-mail institucional, telefone ou outro meio de comunicação. 
Com relação à troca de arquivos, os participantes da pesquisa responderam que utilizam principalmente o aplicativo de troca de mensagens do Microsoft Teams, seguido pelo e-mail institucional e pelo aplicativo de troca de mensagens Whatsapp. O Microsoft Teams também foi reconhecido como o instrumento tecnológico mais seguro para a troca de arquivos e informações.

A maioria dos pesquisados (59\%) informou que não há distinção entre o meio tecnológico utilizado para troca de informações entre membros da equipe com base em características do processo judicial. Ou seja, o fato de se tratar de matéria criminal, cível ou mesmo com a existência de dados sigilosos ou sensíveis não influencia na escolha do instrumento de troca de informações e arquivos entre os membros das equipes de trabalho.

Foi identificado ainda que $97 \%$ dos pesquisados utiliza aparelho móvel (celular) para a troca de informações e arquivos com membros da equipe virtual. Desse total, 39\% (11) utilizam para a troca de qualquer tipo de arquivo ou processo, independente da matéria e $36 \%$ (10) não o utilizam quando os processos possuem dados sigilosos ou sensíveis. O percentual de 18\% (5) utiliza o aparelho móvel apenas para troca de informações, não compartilhando arquivos e 7\% (2) utilizam apenas para troca de informações e somente em casos urgentes.

A pesquisa, mesmo alcançando apenas uma pequena parcela dos juízes e juízas federais em atividade, serve como início de questionamento sobre situações relevantes que precisam ser enfrentadas ante a consolidação das atividades desempenhadas pelo Poder Judiciário no âmbito virtual.

Essa nova forma de atuação apresenta-se como objetivo estabelecido pelo Conselho Nacional de Justiça, que editou as Resoluções $n^{\circ} 335,345$ e 354, todas de 2020, as quais integram o denominado eixo da "Justiça 4.0 e de promoção do acesso à justiça digital". A Resolução no 345 trata sobre o juízo $100 \%$ digital e a no 354 dispõe sobre o cumprimento e realização de atos virtualmente.

Por sua vez, a Resolução n 335/2020, dentre outras disposições, cria a Plataforma Digital do Poder Judiciário Brasileiro - PDPJ-Br, que deve funcionar como modelo de convergência para todos os sistemas de processo judicial eletrônico do Poder Judiciário Nacional. O objetivo é modernizar a plataforma do Processo Judicial Eletrônico, possibilitando que diversos serviços de interesse dos Tribunais e da atividade jurisdicional possam ser nela disponibilizados. 
Consigne-se que a referida resolução estabelece a proibição de contratação por tribunais de sistemas privados que gerem dependência tecnológica. Isso realça a necessidade de que não apenas os sistemas de processamento eletrônico de demandas judiciais, como o PJE, sejam públicos e sem dependência tecnológica, mas, de igual forma, os sistemas de gestão de pessoas e de processos internos, que deve incluir um adequado tratamento dos dados e informações.

É, pois, imperiosa a adoção de técnicas de gestão e desenvolvimento ou adoção de ferramentas tecnológicas que permitam a segurança na transferência das informações, para a garantia da efetividade da atividade judicial e proteção à intimidade das partes envolvidas.

\subsection{Riscos da comunicação em sistemas de informática e telemática}

A adoção do processo judicial eletrônico possibilita a implantação de fluxos padronizados e o controle de dados sigilosos. Destaque-se que a atualização do PJE que é utilizado pelo Tribunal Regional Federal da $1^{\text {a }}$ Região traz cinco novos níveis de sigilo na tramitação processual (NUPJE / SECJU TRF1, 2020). Dessa forma, há restrição maior do acesso aos elementos contidos nos autos eletrônicos, com o controle pelo usuário de maior nível.

Mesmo com adoção desses sistemas de proteção, permanecem relevantes os riscos oriundos do fato de que a tecnologia empregada é conectada à internet. Esse aspecto aumenta as chances de vazamento de dados e informações, com alcance imensurável.

Toda organização que manipula dados pessoais tem a obrigação de garantir o seu adequado tratamento. Para tanto, imprescindível a adoção de métodos eficientes que possibilitem a manutenção dos elementos obtidos, como forma de que sejam utilizados apenas para as finalidades institucionais, com a preservação da intimidade de quem a eles está relacionado.

A natureza das atividades desenvolvidas pelo Poder Judiciário justifica uma rigorosa sistematização do tratamento dos dados que ingressam na organização, notadamente quando estiverem ligados a processos que tratem sobre aspectos relativos à vida privada dos indivíduos ou de interesse público relevante, como ocorre no âmbito do processo criminal. 
O eventual vazamento de dados e informações impacta diretamente na efetividade de algumas medidas judiciais e também pode acarretar na própria violação a direitos, gerando, inclusive, responsabilização do Estado.

Apenas para fins de exemplificação, relembre-se que o Brasil já foi condenado pela Corte Interamericana de Direitos Humanos - CIDH, no ano de 2009, no caso Escher e outros vs. Brasil, tendo por um dos fundamentos exatamente a divulgação indevida pelos meios de comunicação de dados pessoais que foram obtidos por meio de interceptações telefônicas autorizadas judicialmente. Essas interceptações atingiram membros de associação e cooperativa agrícolas ligadas ao movimento dos trabalhadores sem-terra no estado do Paraná (CABACINHA, 2020).

O Brasil foi condenado por ter sido reconhecido que houve violação à norma disposta no art. 11 da Convenção Americana de Direitos Humanos - CADH, que trata da vida privada, ante a grande exploração pela imprensa de dados que haviam sido obtidos de interceptações telefônicas.

Em período mais recente, episódio conhecido como "vazajato", em alusão direta à operação lava-jato da Polícia Federal, reforçou a importância do debate sobre os limites do contato entre os órgãos que compõem o sistema de justiça criminal, mas também suscitou discussões acerca da segurança dos instrumentos tecnológicos utilizados para o desempenho das atividades profissionais dos seus membros.

Os agentes públicos envolvidos no episódio utilizavam aplicativo privado de troca de mensagens (Telegram) para tratarem de assuntos relativos a investigações e processos judiciais em curso. Por meio de invasão desautorizada dos dispositivos de informática, houve o acesso a centenas de mensagens que eram trocadas entre eles. Essas mensagens foram integralmente divulgadas por um sítio eletrônico denominado "The Intercept_Brasil”, com o escopo de deslegitimar a referida operação policial e os processos judiciais que dela decorreram, colocando em risco a própria credibilidade das instituições públicas.

Passando ao largo da discussão acerca da correção da conduta dos agentes públicos envolvidos, deve ser reconhecida a necessidade de um adequado gerenciamento de riscos quanto à atividade de troca de informações no desenvolvimento das atividades do sistema de justiça. Isso inclui as informações compartilhadas entre os membros das equipes de trabalho internas de cada órgão, máxime quando essas equipes não atuam mais em sua integralidade de 
forma presencial, passando a utilizar necessariamente sistemas telemáticos para a comunicação.

\subsection{Métodos e instrumentos para uma comunicação eficiente e segura no âmbito virtual}

A gestão de risco é um elemento essencial ao desenvolvimento de qualquer planejamento estratégico organizacional. A inserção desse gerenciamento de risco à gestão dos processos de negócios (business process management - BPM) facilita a organização e estruturação das ações necessárias ao alcance dos objetivos da organização.

O BPM vem sendo utilizado não só em organizações privadas, mas também públicas e no próprio Poder Judiciário como forma de tentar diminuir as não conformidades em cada etapa que integra o processo produtivo. Davenport (1993) identifica o BPM como esse conjunto estruturado de ações que estabelece de forma clara cada ação que compõe as etapas do processo, com o escopo de alcançar uma finalidade específica.

Com a atual fluidez e imaterialidade de parte dos elementos que compõem as atividades desenvolvidas pelas organizações, torna-se ainda mais importante uma adequada gestão do risco e sua incorporação ao processo produtivo.

A gestão de risco do ato de comunicação entre os membros das equipes de trabalho virtuais no Poder Judiciário precisa do delineamento de processos internos que levem em consideração as peculiaridades dos dados e informações que estão sendo repassadas, bem como a natureza do processo judicial.

Com efeito, ainda que apenas parte da equipe esteja atuando de forma remota, o plano virtual online vem sendo utilizado como o meio principal para a comunicação entre os membros da equipe e para a centralização da gestão do conhecimento. Para tanto, a escolha de um instrumento tecnológico adequado e institucionalmente aceito é medida que se impõe.

A ferramenta de comunicação disponibilizada formalmente pelo Tribunal Regional da $1^{\text {a }}$ Região é o programa computacional fornecido pela empresa Microsoft, denominado Microsoft 365, que inclui diversos programas, entre eles o Microsoft Teams. Apesar disso, a pesquisa realizada para o presente estudo indicou que a ausência de regras claras para seu uso pode ter acarretado na troca de informações relevantes relativas, por exemplo, a processos sigilosos, por ferramentas tecnológicas diversas, cuja segurança não pode ser garantida e que não foram institucionalmente designadas para esse fim. 
Foram utilizados aplicativos de celular de trocas de mensagens (Whatsapp) e até mesmo emails particulares para o compartilhamento de informações entre as equipes virtuais. Assim, dados sensíveis de jurisdicionados e demais usuários dos serviços do Poder Judiciário foram compartilhados sem as devidas cautelas e protocolos de segurança.

Ainda que também se trate de instrumento tecnológico disponibilizado por empresa privada, o fato de o Micrososft 365 ter sido o programa computacional adotado pelo Tribunal Regional Federal da $1^{a}$ Região confere a ele a legitimidade aos fins propostos. Nada impede, porém que outros programas sejam utilizados e até que seja desenvolvido um programa computacional próprio pelo Poder Judiciário. O que é importante é que a comunicação seja realizada de forma exclusiva ou ao menos prioritária por esse programa, como forma de ampliar o controle e gerenciamento de riscos.

Uma ferramenta dessa natureza permite a gestão da equipe de forma remota, servindo também como central de gestão do conhecimento. A atuação de equipes de trabalho no âmbito virtual segue uma lógica própria, que tem na adaptação das formas de comunicação um de seus principais elementos.

Como apresentado na pesquisa realizada, a maioria dos juízes utiliza aplicativos de troca de mensagens instantâneas (Whatsapp e chat do Microsoft Teams) para tratar sobre todos os tipos de assuntos relacionados à gestão processual. Ocorre que a falta de organização dessas mensagens possibilita que informações sejam perdidas, bem como seja gerada uma pretensão de imediatismo no recebimento e resposta às referidas mensagens que não é compatível com a autonomia e flexibilidade inerentes ao trabalho remoto.

A criação de grupos em aplicativos de trocas de mensagem instantânea também não se apresenta como forma tecnicamente adequada para compartilhamento de informações, pois elas costumam ser compartilhadas nesse ambiente de forma solta e desconexa, uma vez que esses instrumentos foram desenvolvidos para essa finalidade, comunicação informal e imediata.

Assim, o adequado é que sejam organizados canais com tópicos estruturados dentro da central de gestão do conhecimento e informação no ambiente virtual online. Nesses canais devem ser inseridas as tarefas e informações tidas por relevantes para cumprimento de cada objetivo proposto no planejamento estratégico da unidade.

Os canais devem ser moldados de acordo com as necessidades da organização, levando em consideração principalmente a urgência da matéria. A comunicação assíncrona 
deve ser adotada como regra, porque ela está em consonância com a maior flexibilidade do trabalho remoto. Assim, em razão da existência de matérias e atos aos quais devem ser conferidos tempos de resposta e atuação diferenciados, deve haver uma estruturação dos canais de comunicação de modo que cada integrante da equipe saiba o momento exato em que deve buscar a informação e praticar o ato decorrente dela.

A comunicação escrita deve prevalecer no gerenciamento de equipes virtuais, mesmo que ela ocorra de maneira informal e direta. A utilização de aplicativos de trocas instantâneas de mensagens (chats) deve ser feita apenas para assuntos que efetivamente necessitem de uma resposta imediata e de baixa complexidade. Os demais assuntos devem ser inseridos nos canais com os tópicos estruturados que permitem um resgate completo e adequado da informação.

Em relação a arquivos contendo documentos de processos judiciais ou investigações policiais em curso, é importante que sejam alocados em bancos de dados seguros e institucionalmente aceitos pelo Tribunal, disponíveis em ambiente online (nuvem). Deve-se evitar, portanto, que sejam compartilhados entre os membros da equipe, com o escopo de conter os riscos de vazamento. Assim, deve ser conferida autorização de acesso aos aludidos bancos de dados aos membros da equipe designados para manuseá-los, como forma de controle do seu conhecimento.

Como já exposto, o trabalho remoto acarreta na redução ou eliminação de reunião física das pessoas no ambiente de trabalho. A desmaterialização do local de trabalho pode prejudicar o compartilhamento de dificuldades e trocas de conhecimentos. Para superar a problemática, mantendo o engajamento da equipe, é necessário que o gestor esteja em contato constante com os seus integrantes, exercendo a chamada escuta ativa, individualmente e também por meio de reuniões periódicas, que podem ocorrer com a utilização de instrumentos tecnológicos de videoconferência.

\section{CONSIDERAÇÕES FINAIS}

A virtualização das atividades desenvolvidas pelo Poder Judiciário, que se apresenta como objetivo bem definido pelo Conselho Nacional de Justiça, acarreta em uma necessária mudança cultural quanto à gestão de seu quadro de pessoal. 
Dentre os diversos aspectos relacionados à gestão de pessoas, a consolidação de equipes virtuais no Poder Judiciário suscita questões relevantes quanto à adequada comunicação entre seus membros, por meio de instrumentos tecnológicos eficazes e seguros.

A fixação de processos internos bem delineados e claros permite a gestão de riscos quanto ao tratamento das informações obtidas pelo Poder Judiciário e compartilhadas entre os membros das equipes virtuais.

Pesquisa realizada para o presente artigo evidenciou a necessidade de uma padronização na gestão do conhecimento e comunicação, por meio de regulamentação mais abrangente da cúpula do Judiciário. Não obstante se trate de dados coletados em pequena parcela dos magistrados e magistradas federais em atividade, é possível extrair um indicativo de que a forma de comunicação com as equipes virtuais depende do modelo escolhido pelo gestor da unidade judiciária.

Foram apresentados alguns riscos às atividades desenvolvidas pelo Poder Judiciário oriundos da ausência de tratamento adequado da informação e utilização de métodos eficientes de comunicação, como a exposição indevida de dados sensíveis, a falta de coordenação entre as informações trocadas, tornando o trabalho ineficiente, além de causar uma sensação de falta de direcionamento dos servidores, dificultando a motivação e coordenação dos trabalhos dos servidores.

Tendo por base esses riscos, delinearam-se algumas ideias preliminares sobre a gestão de equipes virtuais, com ênfase no aspecto relacionado à comunicação eficiente e segura entre seus membros. Foi proposta a estruturação de canais virtuais para a centralização das informações que devem ser compartilhadas entre os membros das equipes virtuais, bem como a utilização apenas de instrumentos tecnológicos autorizados pelo respectivo Tribunal.

O presente estudo necessita de maior amplitude em sua pesquisa para que possam ser obtidos dados adicionais relativos aos métodos de gestão das equipes virtuais que estão sendo utilizados pelos magistrados e magistradas não apenas da Justiça Federal, mas de todo o Poder Judiciário. Isso permitirá uma visão mais abrangente sobre o problema da gestão da informação em equipes virtuais. Desse modo, será possível desenvolver propostas de métodos e instrumentos para uma comunicação eficiente e segura que possam servir como padrão de atuação a ser seguido, sem descurar das peculiaridades de cada ramo do Poder Judiciário.

\section{REFERÊNCIAS}


AKUTSU, Luiz; GUIMARÃES, Tomás de Aquino. Dimensões da governança judicial e sua aplicação ao sistema judicial. Revista Direito GV, São Paulo, v. 15, n. 1, jan./jun. 2017, pp. 183-202.

ALBUQUERQUE, Luis Ezcurra de. Líderes Digitales: Las clavespara liderar com êxito equipos virtuales. Una guia para sobrevivir como líder em la post-pandemia. Espanha. Sociedad Library of Congress. 2020

BRESSER-PEREIRA, Luiz Carlos. O modelo estrutural de gerência pública. Em Revista de Administração Pública - FGV, vol. 42, Rio de Janeiro, março/abril/2008, pp. 391-410.

BRASIL. INSTITUTO BRASILEIRO DE GEOGRAFIA E ESTATÍSTICA - IBGE.

Disponível em: http://www.ibge.gov.br/estatisticas/economicas/contas-nacionais/9300contas-nacionais-trimestrais.html?=\&t=series-

historicas\&utm_source=landing\&utm_medium=explica\&utm_campaign=pib\#evolucao-taxa. Acesso em 10 jul. 2021.

CABACINHA, Paulo Máximo de Castro. O Poder Judiciário Nacional e a Corte

Interamericana de Direitos Humanos: Diálogo ou indiferença? Belo Horizonte: Arraes Editores, 2020.

CHAER, Ana Carolina Lemos, AZEVEDO, Joel Sólon Farias de, BONIFÁCIO, Ivan Gomes. PROJETO DE GESTÃO ESTRATÉGICA DO PODER JUDICIÁRIO DO BRASIL. II Congresso Consad de Gestão Pública - Painel 24: Gestão estratégica no setor público federal: experiências e tendências, Brasília, maio/2009, pp. 1-15.

CHIAVENATO, Idalberto. Gerenciando com as pessoas: transformando o executivo em um excelente gestor de pessoas. 5. ed. Barueri, SP: Manole, 2015.

CNJ, Conselho Nacional de Justiça. Relatório Justiça em números 2020: ano-base 2019. Brasília: CNJ, 2020. 267 p. Disponível em: https://www.cnj.jus.br/wpcontent/uploads/2020/08/WEB-V3-Justi\%C3\% A7a-em-N\%C3\%BAmeros-2020-atualizadoem-25-08-2020.pdf. Acesso em: 20 jan. 2021.

FARIAS, James Magno Araújo. O Uso de Meios Eletrônicos Pelo Direito Processual Brasileiro Durante a Pandemia da COVID-19. Revista de Ciências Jurídicas e Sociais -

IURJ, vol. 1, no. 1, p. 96-103, 18 Sep. 2020. https://doi.org/10.47595/2675-

634x.2020v1i1p96-103.

HADDAD, Carlos Henrique Borlido; PEDROSA, Luís Antônio Capanema. Manual de Administração Judicial. Florianópolis: Editora Tribo da Ilha, 2017. 
HOEGL, Martin, GEMUENDEN, Hans Georg. Teamwork Quality and the Sucess of Innovative Projects: A Theorical Concept and Empirical Evidence. Organization Science. v. 12. n. 4. jullho/agosto 2001, pp. 435-449.

HUGHES, Owen. Does Governance Exist? in OSBORNE, Stephen P (ed.). The New Public Governance? Emerging perspectives in the theory and practice of public governance. London: Routledge, 2010, pp. 87-104.

LÉVY, Pierre. O que é o virtual. trans. by Paulo NEVES. [S. l.]: Editora 34, 2011.

MAGRANI, Eduardo. Entre dados e robôs - Ética e privacidade na era da

hiperconectividade. Porto Alegre: Arquipélago Editorial, 2019.

MOTTA, Paulo. Revendo estrategicamente as organizações do Poder Judiciário: uma perspectiva gerencial. In Cadernos FGV Projetos n. 12 - Poder Judiciário e Gestão Eficiente. Rio de Janeiro: FGV Projetos, maio/junho 2010, pp. 24-31

NUPJE / SECJU TRF1. Entenda os novos níveis de sigilo do PJe 2.1.8.0. . Brasilia: [s.n.]. , 2020

PARDINI, Daniel Jardim; GONÇALVES, Carlos Alberto; PAIVA, Ângela Maria Martins; DIAS, Alexandre Teixeira. Os Significados da Virtualização do Trabalho: Manifestações Discursivas das Percepções Tecnológicas, Processuais e Pessoais nas Relações Intraorganizacionais. Cad. EBAPE,BR, vol. 11, no. 1, p. 85-103, 2013. Available at: http://bibliotecadigital.fgv.br/ojs/index.php/cadernosebape/article/view/7194/pdf_34. Accessed on: 19 Nov. 2020.

PEIXOTO, Fabiano Hartmann. Inteligência Artificial e Direito: Convergência Ética e Estratégica. Curitiba: Alteridade Editora, 2020.

SAUERBRONN, Fernanda Filgueiras, SAUERBRONN, João Felipe Rammelt, GANGEMI, Pedro Paulo de Toledo, FERNANDES, Janaína de Mendonça. Estratégia e gestão do Poder Judiciário: uma proposta de estudo das práticas sociais relacionadas ao BSC. Revista do Serviço Público, n. 67 (1), Brasília, jan/mar. 2016, pp. 7-30

SILVA, Ana Cristina Monteiro de Andrade. Gestão de Pessoas no setor público: uma experiência do poder judiciário. Curitiba: Alteridade Editora, 2020.

TOWSEND, Anthony M., DEMARIE, Samuel M., HENDRICKSON, Anthony R. Virtual

Teams: Technology and the Workplace of the Future. The Academy of Management Executive (1993-2005), v. 12, n. 3. Agosto/1998. pp. 17-29. Disponível em: https://lib.dr.iastate.edu/cgi/viewcontent.cgi?article=1054\&context=management_pubs. 
Acessado em 10 de julho de 2021

THE INTERCEPT_BRASIL. Leia todas as reportagens que o intercept e parceiros

produziram para a vaza jato Disponível em: https://theintercept.com/2020/01/20/linha-dotempo-vaza-jato/. acessado em 11 de julho de 2021

TREMBLAY, Diane-Gabrielle. ORGANIZAÇÃO E SATISFAÇÃO NO CONTEXTO DO

TELETRABALHO. RAE - Revista de Administração de Empresas, São Paulo, vol. 42, no. 3, p. 54-65, 2002. . 